\title{
Synergistic Effects of Cyclic AMP-Related Vasodilators and the Phosphatase Inhibitor Okadaic Acid
}

\author{
Asaki Abe ${ }^{\#}$ and Hideaki Karaki* \\ Department of Veterinary Pharmacology, Faculty of Agriculture, The University of Tokyo, Bunkyo-ku, Tokyo 113, Japan \\ Received May 24, 1993 Accepted July 20, 1993
}

\begin{abstract}
The phosphatase inhibitor okadaic acid at $100 \mathrm{nM}$ slowly but completely inhibited high $\mathrm{K}^{+}$-induced contraction in the rat aorta $\left(\mathrm{t}_{1 / 2}=118.9 \mathrm{~min}\right)$. High $\mathrm{K}^{+}$-induced contraction was partially inhibited (to 37-65\%) by $1 \mu \mathrm{M}$ forskolin, $100 \mu \mathrm{M}$ dibutyryl cyclic AMP, $100 \mathrm{nM}$ atrial natriuretic peptide, 1 $\mu \mathrm{M}$ nitroglycerin, $10 \mathrm{nM}$ sodium nitroprusside, $300 \mathrm{pM}$ nicardipine or $100 \mathrm{nM}$ verapamil. The rate of relaxation due to okadaic acid became faster when the contraction was partially inhibited by these compounds. Augmentation of the relaxation was greater with forskolin and dibutyryl cyclic AMP than with the other inhibitors. These results support the suggestion that okadaic acid inhibits phosphatase to augment the phosphorylation due to cyclic AMP-dependent kinase, resulting in smooth muscle relaxation.
\end{abstract}

Keywords: Okadaic acid, Cyclic AMP, Smooth muscle (vascular)

Okadaic acid is a potent inhibitor of protein phosphatases, inhibiting type $2 \mathrm{~A}$ phosphatase at lower concentrations and type 1 phosphatase at higher concentrations $(1,2)$. In smooth muscle, okadaic acid has concentrationdependent dual effects. At concentrations higher than 1 $\mu \mathrm{M}$, okadaic acid induces contraction $(3,4)$ by phosphorylating the myosin light chain (5). At lower concentrations, in contrast, okadaic acid inhibits contractions induced by high $\mathrm{K}^{+}$-depolarization and receptor agonists $(6-8)$. Since the characteristics of the inhibitory effect of okadaic acid are similar to those of cyclic AMP-related relaxants such as forskolin and dibutyryl cyclic AMP (dbcAMP), it has been suggested that okadaic acid may inhibit phosphatases and thus increase the cyclic AMP-dependent protein phosphorylation (6). If this is the case, the effect of okadaic acid should be augmented when the cyclic AMP level is increased, and testing this hypothesis was the purpose of the present experiments.

Male Wistar rats $(200-250 \mathrm{~g})$ were killed by a sharp blow on the neck and exsanguination. The thoracic aorta was isolated and cut into transverse strips (2-mm-wide and 5-mm-long). Endothelium was removed by gently rubbing the intimal surface with a finger moistened with physiological salt solution which contained $136.9 \mathrm{mM} \mathrm{NaCl}$,

\footnotetext{
" Present address: Department of Animal Science, Faculty of Agriculture, Okayama University, Okayama 700, Japan.

* To whom correspondence should be addressed.
}

$5.4 \mathrm{mM} \mathrm{KCl}, 1.5 \mathrm{mM} \mathrm{CaCl}_{2}, 1.0 \mathrm{mM} \mathrm{MgCl}_{2}, 23.8 \mathrm{mM}$ $\mathrm{NaHCO}_{3}, 0.01 \mathrm{mM}$ ethylenediaminetetraacetic acid and $5.5 \mathrm{mM}$ glucose. High $\mathrm{K}^{+}$solution was made by substituting $60 \mathrm{mM} \mathrm{NaCl}$ with equimolar $\mathrm{KCl}$. These solutions were saturated with a $95 \% \mathrm{O}_{2}$ and $5 \% \mathrm{CO}_{2}$ mixture at $37^{\circ} \mathrm{C}$ to maintain the $\mathrm{pH}$ at 7.4 .

Okadaic acid was donated by Dr. D. Uemura, Shizuoka University and nitroglycerin, by Nippon Kayaku Co., Tokyo. Other chemicals used were forskolin, nicardipine, verapamil (Sigma Chemical Co., St. Louis, MO, USA); db-cAMP (Yamasa Shouyu, Tokyo); $\alpha$-human atrial natriuretic peptide (Peptide Institute, Osaka); and sodium nitroprusside (Wako Pure Chemicals, Osaka). Results of the experiments are shown by the mean \pm S.E.M. of the data.

Contractile force was measured with a force-displacement transducer (Nihon Kohden, Tokyo). The muscle preparation was equilibrated for $30 \mathrm{~min}$ in a $10-\mathrm{ml}$ bath. High $\mathrm{K}^{+}$was applied three times, $10 \mathrm{~min}$ each, at a 15 min interval, before starting the experimental procedures. When the contractile force due to the fourth application of high $\mathrm{K}^{+}$reached a steady level, okadaic acid was added. As shown in Fig. 1A, $100 \mathrm{nM}$ okadaic acid slowly and completely relaxed the high $\mathrm{K}^{+}$-induced contraction. The time required to relax the contraction by $50 \%$ (halftime or $\left.t_{1 / 2}\right)$ was $118.9 \pm 5.5 \min (n=12)$. Lower concentrations of okadaic acid inhibited the contraction more slowly $\left(\mathrm{t}_{1 / 2}>120 \mathrm{~min}\right)$, whereas a higher concentration 

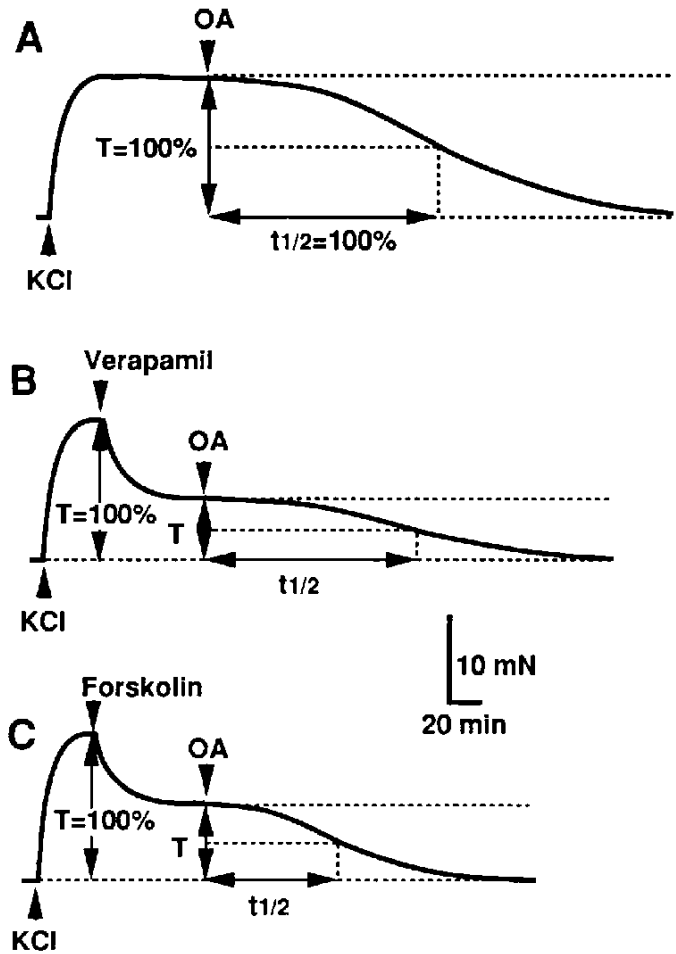

Fig. 1. Effect of $100 \mathrm{nM}$ okadaic acid (OA) on $65.4 \mathrm{mM} \mathrm{K}^{-}$-induced contraction. (A) Okadaic acid was added when the contraction induced by high $\mathrm{K}^{+}$reached a steady level. (B) and (C) During the high $\mathrm{K}^{+}$-induced contraction, $100 \mathrm{nM}$ verapamil or $1 \mu \mathrm{M}$ forskolin was added, and then okadaic acid was added. Muscle contraction before the addition of okadaic acid $(\mathrm{T})$ and time needed to induce a $50 \%$ relaxation $\left(t_{1 / 2}\right)$ are shown by arrows.

(300 nM) more rapidly inhibited the contraction with a shorter $\mathrm{t}_{1 / 2}(58.9 \pm 1.9 \mathrm{~min}, \mathrm{n}=4)$. From these results, we decided to use $t_{1 / 2}$ rather than contractile force as an indicator of the inhibitory effect of okadaic acid.

Previously, we have shown that the relaxant effects of forskolin and db-cAMP are inversely proportional to the magnitude of contractile tension; that is, the relaxant effect is greater when the contraction before the addition of the relaxant was smaller (9). To examine if the inhibitory effect of okadaic acid is also modified by the magnitude of contraction, we partially inhibited the high $\mathrm{K}^{+}$-induced contraction by adding $\mathrm{Ca}^{2+}$ channel blockers. As shown in Fig. 1B, $100 \mathrm{nM}$ verapamil was added during the high $\mathrm{K}^{+}$-induced contraction which inhibited the contraction to a new steady level of $36.5 \pm 2.7 \%(n=4)$. Then $100 \mathrm{nM}$ okadaic acid was sequentially added. In the presence of verapamil, the rate of okadaic acid-induced relaxation became slightly faster. $T_{1 / 2}$ was decreased by $19.2 \mathrm{~min}$ or to $85.0 \%$ of the $t_{1 / 2}$ in the absence of verapamil. Nicardipine $(100 \mathrm{pM})$ showed a similar effect as verapamil, inhibiting the high $\mathrm{K}^{+}$-induced contraction to $52.7 \%$ and decreasing $t_{1 / 2}$ to $82.2 \pm 6.1 \%(n=4)$. The

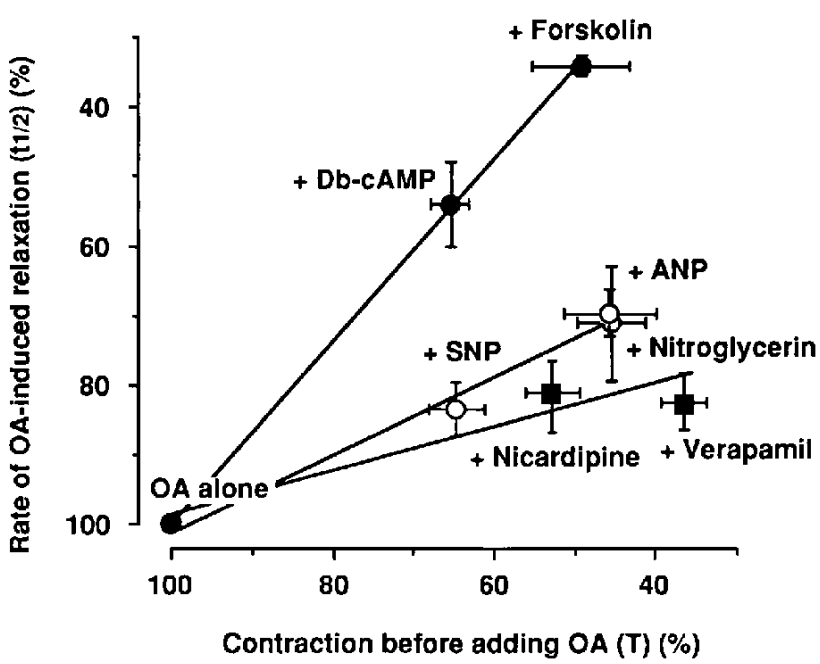

Fig. 2. Effects of various inhibitors on high $\mathrm{K}^{+}$-induced contraction and the relaxant effect of okadaic acid (OA). The experiment was done as shown in Fig. 1. The inhibitor was added during the high $\mathrm{K}^{+}$-induced contraction, and the new steady level ( $\mathrm{T}$ in Fig. 1) is plotted on the abscissa, taking the contraction before the addition of inhibitor as $100 \%$. Okadaic acid was then added, and the rate of relaxation ( $t_{1 / 2}$ in Fig. 1 ) is plotted on the ordinate, taking the $t_{1 / 2}$ in the absence of inhibitor as $100 \%$. Each point represents mean of 4-5 experiments, and S.E.M. is shown by vertical and horizontal bars. The correlation coefficient for the regression line is 1.000 for cyclic AMP-related relaxants $(1 \mu \mathrm{M}$ forskolin and $100 \mu \mathrm{M} \mathrm{db}-$ cAMP: filled circles), 0.990 for cyclic GMP-related relaxants (100 $\mu \mathrm{M}$ atrial natriuretic peptide [ANP], $10 \mathrm{nM}$ sodium nitroprusside [SNP] and $1 \mu \mathrm{M}$ nitroglycerin: open circles), and 0.922 for $\mathrm{Ca}^{2+}$ channel blockers ( $100 \mathrm{nM}$ verapamil and $300 \mathrm{pM}$ nicardipine: filled squares).

relationship between the magnitude of contraction ( $T$ in Fig. 1) and potency of okadaic acid ( $t_{1 / 2}$ in Fig. 1) in Fig. 2 shows that the relaxant effect of okadaic acid is greater when the magnitude of contraction before the addition of okadaic acid was smaller. The similarity between the effects of okadaic acid and cyclic AMP-related vasodilators supports the suggestion that okadaic acid inhibits phosphatase to augment the phosphorylation due to cyclic AMP-dependent kinase.

In the next experiments, we determined if the increase in cyclic AMP level further augments the effect of okadaic acid. To increase the cyclic AMP level, we added forskolin or db-cAMP during the high $\mathrm{K}^{+}$-induced contraction. As shown in Fig. 1C, addition of $1 \mu \mathrm{M}$ forskolin inhibited the high $\mathrm{K}^{+}$-induced contraction to $49.2 \pm 6.1 \%$ $(n=4)$. In the presence of forskolin, the rate of okadaic acid-induced relaxation became faster and shortened $t_{1 / 2}$ to $37.5 \pm 1.4 \%(n=4)$. The effect of db-cAMP was similar to that of forskolin. The relationship between the magnitude of contraction ( $\mathrm{T}$ in Fig. 1) and potency of okadaic acid $\left(t_{1 / 2}\right.$ in Fig. 1) is shown in Fig. 2. The slope of the correlation was steeper in the presence of cyclic AMP-related 
relaxants than in the presence of $\mathrm{Ca}^{2+}$ channel blockers, suggesting that the inhibitory potency of okadaic acid is greatly augmented when the cyclic AMP level is increased.

To determine if the inhibitory effect of okadaic acid is selectively augmented by cyclic AMP, we examined the effects of cyclic GMP. To increase the cyclic GMP level, we used $10 \mathrm{nM}$ sodium nitroprusside, $100 \mathrm{nM}$ atrial natriuretic peptide and $1 \mu \mathrm{M}$ nitroglycerin. As shown in Fig. 2, these compounds inhibited the high $\mathrm{K}^{+}$-induced contraction to $45.4-64.7 \%$ and shortened $t_{1 / 2}$ to $65.1-82.0 \%$ of the respective control level. The slope of the correlation for cyclic GMP-related relaxants is only slightly steeper than that for $\mathrm{Ca}^{2-}$ channel blockers, suggesting that cyclic GMP has only a small, if any, potentiating effect on okadaic acid-induced relaxation. It is generally believed that cyclic GMP activates protein kinase to phosphorylate functional proteins and relaxes smooth muscle. However, the site of action of cyclic GMP seems to be different from that of cyclic AMP because cyclic GMP relaxes smooth muscle with little effect on myosin phosphorylation (11), and cyclic AMP but not cyclic GMP augmented the effect of okadaic acid (present result). It is possible that okadaic acid inhibits the phosphatase antagonizing the cyclic AMP-dependent kinase with little effect on the phosphatase antagonizing the cyclic GMP-dependent kinase.

In the rat aorta, the major mechanism of the effect of cyclic AMP on high $\mathrm{K}^{+}$-induced contraction is to decrease the $\mathrm{Ca}^{2+}$ sensitivity of contractile elements without changing the cytosolic $\mathrm{Ca}^{2+}$ level (9). Cyclic AMP has been shown to inhibit myosin phosphorylation to relax smooth muscle (10). This effect may be antagonized by the increase in cytosolic $\mathrm{Ca}^{2+}(9)$, and this may be the reason why the relaxant effect of cyclic AMP is stronger on a smaller contraction (or in the presence of lower cytosolic $\mathrm{Ca}^{2+}$ level). In the present experiments, we found that the inhibitory effect of okadaic acid is also stronger when the contraction was partially inhibited by $\mathrm{Ca}^{2+}$ channel blockers or nitro-vasodilators. Furthermore, the inhibitory effect of okadaic acid was more strongly augmented when the contraction was partially inhibited by cyclic AMP-related relaxants. These results support the suggestion that okadaic acid inhibits phosphatases and thus augments cyclic AMP-dependent phosphorylation to induce vasodilation. This effect may be antagonized by the increase in cytosolic $\mathrm{Ca}^{2+}$ level and augmented by the increase in cyclic AMP level.

\section{Acknowledgments}

We are grateful to Dr. D. Uemura, Shizuoka University and Nihon Kayaku Co. for the generous gifts of okadaic acid and nitroglycerin, respectively. This work was supported by a Grant-inAid for Scientific Research from the Ministry of Education, Science and Culture, Japan.

\section{REFERENCES}

1 Bialojan, C., Rüiegg, J.C. and Takai, A.: Effects of okadaic acid on isometric tension and myosin phosphorylation of chemically skinned guinea-pig taenia coli. J. Physiol. (Lond.) 398 , $81-95$ (1988)

2 Ishihara, H, Martin, N.L., Brautigan, D.L., Karaki, H., Ozaki, H., Kato, Y., Fusetani, N., Watabe, S., Hashimoto, K. Uemura, D. and Hartshorne, D.J.: Calyculin A and okadaic acid: inhibitors of protein phosphatase activity. Biochem. Biophys. Res. Commun. 159, 871-877 (1989)

3 Shibata, S., Ishida, Y., Kitano, H., Ohizumi, Y., Habon, J., Tsukitani, Y. and Kikuchi, H.: Contractile effects of okadaic acid, a novel ionophore-like substance from black sponge, on isolated smooth muscles under the condition of $\mathrm{Ca}^{2+}$-deficiency. J. Pharmacol. Exp. Ther. 223, 135-143 (1982)

4 Ozaki, H., Kohama, K., Nonomura, Y., Shibata, S. and Karaki, H.: Direct activation by okadaic acid of contractile elements in the smooth muscle of guinea-pig taenia coli. Naunyn Schmiedebergs Arch. Pharmacol. 335, 356-358 (1987)

5 Ozaki, H., Ishihara, H., Kohama, K., Nonomura, Y., Shibata, S. and Karaki, H.: Calcium-independent phosphorylation of smooth muscle myosin light chain by okadaic acid isolated from black sponge (Halichondria okadai). J. Pharmacol. Exp. Ther. 243, 1167-1173 (1987)

6 Karaki, H., Mitsui, M., Nagase, H., Ozaki, H., Shibata, S. and Uemura, D.: Inhibitory effect of a toxin okadaic acid, isolated from the black sponge on smooth muscle and platelets. $\mathrm{Br}$. J. Pharmacol, 98, 590-596 (1989)

7 Ashizawa, N., Kobayashi, F., Tanaka, Y. and Nakayama, K.: Relaxing action of okadaic acid, a black sponge toxin on the arterial smooth muscle. Biochem. Biophys. Res. Commun. 162, 971-976 (1989)

8 Shibata, S., Satake, N., Morikawa, M., Kwon, S.-C., Karaki, H., Kurahashi, K., Sawada, T. and Kodama, 1.: The inhibitory action of okadaic acid on mechanical responses in guinea-pig vas deferens. Eur. J. Pharmacol. 193, 1-7 (1991)

9 Abe, A. and Karaki, H.: Mechanism underlying the inhibitory effect of dibutyryl cyclic AMP in vascular smooth muscle. Eur. J. Pharmacol. 211, 305-311 (1992)

10 Tang, D.-C., Stull, J.T., Kubota, Y. and Kamm, K.E.: Regulation of the $\mathrm{Ca}^{2+}$ dependence of smooth muscle contraction. J. Biol. Chem. 267, $11839-11845$ (1992)

11 McDaniel, N.L., Chen, X.-L., Singer, H.A., Murphy, R.A. and Rembold, C.M.: Nitrovasodilators relax arterial smooth muscle by decreasing $\left[\mathrm{Ca}^{2+}\right]_{\mathrm{i}}$ and uncoupling stress from myosin phosphorylation. Am. J. Physiol. 263, C461-C467 (1992) 